\title{
La coordinación entre la responsabilidad concursal y la responsabilidad societaria en Derecho español
}

\author{
Judith Morales Barceló' \\ Universidad de Barcelona \\ jmorales@ub.edu
}

Fecha de recibido: octubre 2016 / Fecha de aprobación: diciembre 2016

La convivencia en Derecho español de un régimen de responsabilidad societaria y un régimen de responsabilidad concursal exigible a los administradores de sociedades mercantiles, genera ciertas dudas cuando éstas se encuentran incursas en un procedimiento concursal. En este artículo se van a analizar las diferentes posturas doctrinales y jurisprudencias sobre los efectos del procedimiento concursal en la responsabilidad por deudas ex artículo 367 de la Ley de Sociedades de Capital y en la responsabilidad por daños ex artículos 238 y $24 \mathrm{I}$ de la misma Ley. Así mismo, se va a analizar la posible coordinación de estas responsabilidades con la responsabilidad concursal, exigible en supuestos en los que una sociedad mercantil se encuentre en situación de insolvencia.

\section{Palabras Clave}

Responsabilidad / insolvencia /administradores sociales / sociedades mercantiles

\section{Abstract}

The coexistence in Spanish law of a regime of director's liability and a bankruptcy liability required to corporate directors generates some doubts when the corporates are incurred in a bankruptcy proceeding. In this article we are going to analyze the different doctrinal positions and court decisions on the effects of insolvency proceedings on the liability for debts ex article 367 of the "Ley de Sociedades de Capital" and the liability for damages ex articles 238 and $24 \mathrm{I}$ of the same Act. As well, we are going to analyze the possible coordination of these liabilities and the bankruptcy, in case the corporation is in this situation

\section{Key words}

Liability / bankruptcy / directors / corporations

Profesora lectora del Departamento de Derecho Mercantil, Derecho del Trabajo y de la Seguridad Social de la Facultad de Derecho de la Universidad de Barcelona 


\section{Tabla de contenido}

I. Introducción. 2. La acción de responsabilidad por deudas y el procedimiento concursal. 2.I. Delimitación del ámbito objetivo. 2.2. Efectos de la declaración de concurso. 2.3. Coordinación con la responsabilidad concursal. 3. La acción social de responsabilidad y el procedimiento concursal. 3.I. Efectos de la declaración de concurso. 3.2. Coordinación con la responsabilidad concursal. 4. La acción individual de responsabilidad y el procedimiento concursal. 4.I. Efectos de la declaración de concurso. 4.2. Coordinación con la responsabilidad concursal. 5. Conclusiones.

\section{Introducción}

El ordenamiento jurídico español distingue dos regímenes de responsabilidad exigible a los administradores de las sociedades mercantiles, en atención a si la sociedad que administran se encuentra incursa en un procedimiento concursal, como consecuencias de una situación de insolvencia. Un primer régimen es aquel exigible a la luz de la responsabilidad concursal, cuando la sociedad ha sido declarada en concurso. $Y$ un segundo régimen es aquel exigible en atención al Real Decreto Legislativo 1/2010, de 2 de julio, por el que se aprueba el texto refundido de la Ley de Sociedades de Capital (en adelante LSC), ya sea cuando la sociedad se encuentra en una causa de disolución obligatoria o bien cuando el administrador social ha causado un daño a la sociedad y/o terceros. En este sentido, resulta de especial relevancia determinar si durante el desarrollo de un procedimiento concursal es posible exigir al mismo tiempo la responsabilidad concursal y ejercitar alguna de las acciones de responsabilidad societaria, así como determinar qué efectos tendrá la declaración de concurso sobre las acciones societarias que han sido ejercitadas con anterioridad al inicio del procedimiento concursal.

Por un lado, como es sabido, la responsabilidad concursal es aquella, prevista en el artículo I72 bis Ley 22/2003, de 9 de julio, Concursal (en adelante LC), que posibilita condenar a los administradores, en el desarrollo de un procedimiento concursal que finaliza en liquidación, a cubrir, total o parcialmente, el déficit concursal, cuando la conducta que ha determinado la calificación culpable del concurso haya generado o agravado la situación de insolvencia. En este sentido, analizaremos en qué situaciones será procedente condenar a los administradores como responsables desde un punto de vista societario y además concursal.

Y por otro, el artículo 236 LSC establece el marco de la responsabilidad de los administradores de carácter indemnizatorio. Esta responsabilidad, tiene como finalidad resarcir los daños ocasionados tanto a la sociedad como a los accionistas y terceros. En atención a los destinatarios de la indemnización es posible distinguir entre la acción social y la acción individual de responsabilidad. La acción social, prevista en el artículo 238 LSC, está dirigida a resarcir el patrimonio de la sociedad. Y la acción individual, prevista en el artículo 24I LSC, está dirigida a resarcir el patrimonio individual de los accionistas y terceros. Los actos u omisiones de los administradores, realizados con dolo o culpa, que causen los daños objeto de resarcimiento deben ser contrarios a la ley, a los estatutos o realizados incumpliendo los deberes inherentes a su cargo.

El artículo 367 LSC prevé un supuesto de responsabilidad por deudas. Los administradores son responsables de las deudas sociales, posteriores al acaecimiento de una causa de disolución, ante el incumplimiento de 
determinados deberes dirigidos a la promoción de la disolución de la sociedad en supuestos en los que ésta es obligatoria.

La responsabilidad por deudas será la primera que analizaremos, puesto que su ámbito objetivo, que permite a los acreedores el cobro de los créditos posteriores al acaecimiento de la causa de disolución, puede ser coincidente con el de la responsabilidad concursal. La acción social de responsabilidad será la que analizaremos en segundo lugar, ya que el texto de la LC no ofrece ninguna duda de su compatibilidad con el procedimiento concursal, a pesar de que su ejercicio durante la tramitación del concurso altera las normas de legitimación y competencia del juez. Y finalmente estudiaremos la acción individual de responsabilidad porque el régimen es similar al de la acción social, a pesar de que la LC no se pronuncia sobre ella.

Es posible avanzar que no parece existir ninguna duda sobre la posibilidad de ejercitar la acción social de responsabilidad durante el desarrollo del procedimiento concursal $y$, por tanto, la compatibilidad con la responsabilidad concursal, puesto que lo admite de forma expresa el artículo 48 quater LC. Sin embargo, mayores problemas presenta la compatibilidad del ejercicio de la acción individual de responsabilidad, puesto que la LC no lo admite de forma expresa. Esto es relevante, ya que esta responsabilidad afecta de forma directa a la satisfacción de los acreedores que es la finalidad del procedimiento concursal. Tanto la doctrina mayoritaria y las resoluciones judiciales son favorables a la posibilidad de ejercitar las acciones de responsabilidad durante el procedimiento concursal. No obstante, en nuestra opinión, las finalidades del procedimiento impedirían el ejercicio de estas acciones societarias durante la tramitación del mismo.

\section{La acción de responsabilidad por deudas y el procedimiento concursal}

\section{I. Delimitación del ámbito objetivo}

El artículo 367 LSC contempla un régimen de responsabilidad de los administradores por deudas sociales ante el incumplimiento de ciertos deberes relativos a la promoción de la disolución de la sociedad, por tanto, esta responsabilidad es exigible ante la concurrencia de dos presupuestos: en primer lugar, la existencia de una causa legal o estatutaria de disolución; $y$ en segundo lugar, el incumplimiento de los deberes legales contemplados en el artículo 367 LSC2.

En cuanto a las causas de disolución, debemos destacar la situación de pérdidas graves, puesto que además de ser la más frecuente, es aquella que estará vinculada con la situación de insolvencia. La situación de pérdidas es indicador en la mayor parte de casos de una situación de grave crisis económica. De este modo, la doctrina y la jurisprudencia han otorgado a esta causa de disolución obligatoria una función pre concursal o medida preventiva, puesto que trata de evitar que la sociedad llegue a la situación de insolvencia y de que se inicie el procedimiento

\footnotetext{
${ }^{2}$ El texto del apartado 1 del artículo 367 LSC es el siguiente: "Responderán solidariamente de las obligaciones sociales posteriores al acaecimiento de la causa legal de disolución los administradores que incumplan la obligación de convocar en el plazo de dos meses la junta general para que adopte, en su caso, el acuerdo de disolución, así como los administradores que no soliciten la disolución judicial o, si procediere, el concurso de la sociedad, en el plazo de dos meses a contar desde la fecha prevista para la celebración de la junta, cuando ésta no se haya constituido, o desde el día de la junta, cuando el acuerdo hubiera sido contrario a la disolución".
} 
concursal mediante la obligación de adoptar un acuerdo de disolución o de remoción de la causa. En la situación de pérdidas graves, el patrimonio neto de la sociedad sigue siendo positivo pero se pretende evitar que esa situación derive en un patrimonio neto negativo y se convierta en una situación de insolvencia. Si por el contrario, la sociedad ya es insolvente, no procederá la disolución de la sociedad sino que el órgano de administración deberá solicitar la declaración de concurso, ya que la finalidad de la disolución o la remoción era precisamente evitar la situación de insolvencia. La LSC admite de forma expresa la posibilidad de un cumplimiento alternativo a la disolución en los supuestos en los que concurra una situación de pérdidas graves y la sociedad se encuentre en estado de insolvencia inminente.

Desde el momento en el que la sociedad se encuentra en alguno de los supuestos de disolución establecidos en el artículo 363 LSC, los administradores deben cumplir con los deberes contemplados en los artículos siguientes. El primero de estos deberes es convocar junta en el plazo de dos meses desde el acaecimiento de la causa de disolución, con un orden del día que incluya un punto en el que se proponga la disolución de la sociedad o bien una medida alternativa por la que se remueva la causa. La junta, una vez constituida, deberá adoptar el acuerdo de disolución o de remoción de la causa. Si por el contrario, la junta no se constituye o bien adopta un acuerdo que es contrario a la disolución y la causa de disolución persiste, el órgano de administración tiene otro plazo de dos meses desde la fecha prevista para la celebración de la junta, cuando no se haya constituido, o desde el día de la junta, cuando el acuerdo no se ha adoptado o se ha adoptado uno contrario a la disolución, para solicitar la disolución judicial. En el caso de sentencia condenatorio de los administradores como responsables ex artículo 367 LSC, éstos deberán asumir las deudas de la sociedad posteriores al acaecimiento de la causa de disolución.

\section{2. Efectos de la declaración de concurso sobre la acción de responsabilidad por deudas}

En este apartado se van a analizar cuáles son las consecuencias del inicio de un procedimiento concursal sobre la acción de responsabilidad por deudas. Para ello, distinguiremos según se haya ejercitado esta acción con anterioridad o bien con posterioridad a la declaración de concurso. La LC se pronuncia de forma expresa sobre la compatibilidad del procedimiento concursal y la responsabilidad por deudas, en el sentido de impedir el ejercicio de la acción dirigida a exigir esta responsabilidad contra los administradores de sociedades declaradas en concurso, así como suspender el procedimiento de las iniciadas si con posterioridad la sociedad es declarada en concurso. En concreto, la respuesta se encuentra en los artículos 50 y $5 \mathrm{I}$ bis LC, cuyos respectivos títulos son: "nuevos juicios declarativos" y "suspensión de juicios declarativos pendientes".

La LC, en su artículo 503, no permite el ejercicio de acciones dirigidas a exigir la responsabilidad por deudas contra administradores de sociedades declaradas en concurso. En este sentido, la ley predica que el juez de lo mercantil no admitirá a trámite las demandas que tengan por objeto reclamar a los administradores por las obligaciones sociales en caso de incumplimiento de los deberes relativos a promover la disolución de la sociedad. En el mismo

\footnotetext{
${ }^{3}$ El artículo 50 LC establece lo siguiente: "Los jueces de lo mercantil no admitirán a trámite las demandas que se presenten desde la declaración del concurso hasta su conclusión, en las que se ejerciten acciones de reclamación de obligaciones sociales contra los administradores de las sociedades de capital concursadas que hubieran incumplido los deberes impuestos en caso de concurrencia de causa disolución. De admitirse, será de aplicación lo dispuesto en el último inciso del apartado anterior". El inciso al que se refiere ordena el archivo de todo lo actuado.
} 
sentido, el artículo $5 \mathrm{I}$ bis LC4 no permite la continuación de los procedimientos de responsabilidad por deudas contra los administradores iniciados con anterioridad a la declaración de concurso.

De esta forma, podemos confirmar que la solución más congruente con la finalidad del procedimiento concursal, y reconocida en la LC, es otorgar preferencia a este procedimiento frente a la responsabilidad por deudas. Así los acreedores no logran burlar la par conditio creditorum, puesto que, como sabemos, la responsabilidad por deudas permite una satisfacción de los créditos de los acreedores, por tanto, quedan sujetos al resultado del concurso para reclamar sus créditos.

En esta misma línea, y en consonancia con lo previsto en la Ley, es posible encontrar un artículo relativo a la interrupción de la prescripción en la exigencia de responsabilidad. En este sentido, merece especial interés el análisis del artículo 60 LC que prevé la interrupción de la prescripción desde la declaración del concurso, con independencia de que la solicite el deudor o un acreedor, hasta la conclusión del mismo5. Esta interrupción afecta a todos los créditos desde el momento en el que se dicta el auto de declaración de concurso, a pesar de que sea un solo acreedor el que haya solicitado la declaración de concurso. El cómputo del plazo de la prescripción se reinicia una vez concluido el concurso. De esta forma, el plazo de prescripción volverá a computarse desde el inicio, puesto que el precepto prevé la interrupción de la prescripción y no la suspensión.

Los efectos de la declaración de concurso sobre la sentencia condenatoria de los administradores como responsables por las deudas sociales ex artículos 367 LSC dependen según el concurso finalice en convenio o en liquidación.

Si el concurso finaliza en convenio, una de las dudas que se plantean es si las quitas, esperas y las renuncias de acciones contra la sociedad acordadas en el convenio afectan a los administradores, que son responsables solidarios de las deudas sociales en aplicación del artículo 367 LSC. En nuestra opinión, para dar respuesta a esta cuestión, debemos analizar lo establecido en el artículo I35 LC: "[l]os acreedores que no hubiesen votado a favor del convenio no quedarán vinculados por éste en cuanto a la subsistencia plena de sus derechos frente a los obligados solidariamente con el concursado y frente a sus fiadores o avalistas, quienes no podrán invocar ni la aprobación ni los efectos del convenio en perjuicio de aquellos. La responsabilidad de los obligados solidarios, fiadores o avalistas del concursado frente a los acreedores que hubiesen votado a favor del convenio se regirá por las normas aplicables a la obligación que hubieren contraído o por los convenios, que sobre el particular hubieran establecido". En atención a este precepto, la LC predica el mantenimiento de la legitimación activa de los acreedores que pueden ejercitar la acción prevista en el artículo 367.I LSC, a pesar de que el concurso finalice en convenio y uno de los acuerdos sea la renuncia a estas acciones para quienes votaron en contra del convenio o bien no lo votaron, si esos acreedores no han votado a favor del convenio (MUÑOZ GARCíA, 2007, p. 203 y BELTRÁN SÁNCHEZ, 20I I, Pp. 303 Y 304) ${ }^{6}$. Sin

\footnotetext{
${ }^{4} \mathrm{El}$ artículo 51 bis LC establece que: "declarado el concurso y hasta su conclusión, quedarán en suspenso los procedimientos iniciados antes de la declaración de concurso en los que se hubieran ejercitado acciones de reclamación de obligaciones sociales contra los administradores de las sociedades de capital concursadas que hubieran incumplido los deberes impuestos en caso de concurrencia de causa de disolución".

${ }^{5}$ El artículo 60 LC establece: "Desde la declaración hasta la conclusión del concurso quedará interrumpida la prescripción de las acciones contra socios y contra administradores, liquidadores y auditores de la persona jurídica deudora por los créditos anteriores a la declaración".

${ }^{6}$ La STS de 23 de febrero de 2004 aplica el artículo 135 LC a los supuestos de responsabilidad ex artículos 262.5 Ley de Sociedades Anónimas, derogada por la LSC. En este sentido, cabe mencionar que este último
} 
embargo, respecto a aquellos acreedores que hubiesen votado a favor del convenio les serán aplicables las quitas y esperas acordadas no sólo frente a la sociedad concursada sino también frente los administradores responsables por las deudas sociales. Y en atención a lo previsto en la segunda parte del artículo I35 LC: “(...) se regirá por las normas aplicables a la obligación que hubieren contraído o por los convenios, que sobre el particular hubieran establecido”.

En nuestra opinión, el artículo I 35 LC es plenamente aplicable a los supuestos de responsabilidad por deudas ex artículo 367.I LSC debido a que los administradores son responsables en la condición de garantes solidarios de las deudas sociales, por lo que la sociedad sigue siendo la deudora. De lege lata debemos atender a si los acreedores han votado a favor del convenio para que las quitas y esperas acordadas tengan también efecto en la responsabilidad de los administradores por las deudas sociales y, a sensu contrario, si los acreedores no han votado a favor del convenio esas quitas y esperas no afectarán a la responsabilidad de los administradores. Sin embargo, de lege ferenda consideramos que si la sociedad ha acordado con los acreedores quitas o esperas, los administradores quedan sometidos a las condiciones de lo acordado y respecto a quienes se ven afectados por la aplicación del convenio, puesto que el administrador no puede deber más que la propia sociedad concursada. De lo contrario, si tan sólo afecta a aquellos acreedores que hayan votado a favor del convenio ésta podría ser una razón que dificultase el acuerdo, ya que los acreedores podrían querer conservar la misma responsabilidad de los administradores en las mismas condiciones que aquellos que no lo han votado o bien han votado en contra. En este punto, querríamos comentar que un sector doctrinal considera que los administradores no se pueden beneficiar de las quitas, las esperas y las renuncias acordadas. Por tanto, que la responsabilidad de los administradores se mantiene con independencia del sentido del voto de los acreedores (RODRÍGUEZ RUIZ DE VILLA, 2004, pp. 102 A I I 7; Bello Martín-Crespo, 2005, p. I 733; MuÑoz PlanAS, J.M. y MuÑOZ PARedes, 2005, p. 2203).

Si el concurso finaliza en liquidación debemos advertir dos posibilidades: que la masa activa sea suficiente para atender todos los créditos o bien que sea insuficiente. Si la masa activa es suficiente, la sociedad no tendrá deudas, por lo que los acreedores no podrán ejercitar la acción de responsabilidad por deudas y aquellos procedimientos iniciados con esta finalidad, que han quedado interrumpidos por la declaración de concurso, deberán finalizar. Si la masa activa es insuficiente y los administradores son condenados como responsables concursales, la totalidad o parte de esos créditos podrán ser satisfechos con la condena ex artículo 172 bis LC de los administradores. Por el contrario, si los administradores no son condenados como responsables concursales o lo son pero tan sólo por una parte de los créditos, los acreedores podrán interponer la acción de responsabilidad por deudas si no lo habían hecho con anterioridad a la declaración de concurso o reanudar el procedimiento iniciado. Sin embargo, la eventual condena de los administradores ex artículo 367.I LSC deberá tener en cuenta el cobro en sede de concurso. En estos supuestos, el administrador que haya efectuado el pago de las deudas sociales no podrá repetir contra la sociedad deudora, puesto que el concurso ha finalizado con su liquidación, por lo que repetirá contra los administradores condenados por la parte proporcional de la responsabilidad.

\section{3. Coordinación de la responsabilidad concursal y la responsabilidad por deudas}

En atención a lo expuesto con anterioridad, es posible afirmar que la LC prevé, sin lugar a dudas, que en aquellas sociedades que se encuentran situación de insolvencia, los administradores deben solicitar la declaración de

artículo contemplaba el régimen de responsabilidad por deudas de los administradores sociales por el incumplimiento de sus obligaciones en caso de que la sociedad se encontrase en alguna causa de disolución obligatoria, de forma muy similar al actual artículo 367 LSC. 
concurso, a pesar de que la sociedad también se encuentre en una causa de disolución por pérdidas graves. Por tanto, la única responsabilidad exigible a los administradores será la concursal. A pesar de ello, consideramos que es relevante realizar un análisis con más detenimiento, distinguiendo entre la situación de insolvencia actual y la insolvencia inminente y el momento en el que hayan surgido las pérdidas graves.

En aquellos supuestos en los que la sociedad se encuentre en situación de pérdidas graves y, al mismo tiempo, en situación de insolvencia actual, tiene preferencia la promoción del procedimiento concursal, puesto que la situación de pérdidas graves queda absorbida por la insolvencia. En este caso, los administradores deben solicitar el concurso de forma obligatoria, sin que se admita la promoción de la disolución a modo de cumplimiento alternativo. La falta de solicitud del concurso permite presumir, salvo prueba en contrario, dolo o culpa grave de los administradores en atención al artículo I65 LC, lo que posibilitará la responsabilidad concursal ex artículo I 72 bis LC, si el concurso es calificado como culpable y finaliza en liquidación. No obstante, si en primer lugar la sociedad se encuentra en situación de pérdidas graves y posteriormente entra en un estado de insolvencia actual, los administradores deben cumplir con los deberes establecidos en los artículos 365 a 367 LSC, dentro de los dos meses siguientes al acaecimiento de la causa de disolución en orden a promover la disolución de la sociedad7. Sin embargo, los administradores deben solicitar la declaración de concurso en el momento en el que la sociedad entre en situación de insolvencia actual, contando para ello con un plazo de dos meses desde que se ha conocido o debido conoce la situación de insolvencia (artículo 5.I LC). De esta forma, la solicitud de concurso no exonera a los administradores de la responsabilidad ex artículo 367 LSC, si no han promovido la disolución cumpliendo con los Plazos establecidos con anterioridad a la solicitud de concurso (SEQUEIRA MARTíN, SACRISTÁN BERGÍA y MUÑOZ GARCÍA, 2006, p. 1748).

En el supuesto en el que la sociedad se encuentra en situación de pérdidas graves y al mismo tiempo en situación de insolvencia inminente es posible, a modo de cumplimiento alternativo, sustituir la promoción de la disolución por la solicitud de declaración de concurso (GONZÁLEZ VÁZQUEZ, 2004, p. 3838; BELTRÁN SÁNCHEZ, 20I I, p. 280). En este supuesto el juez no podrá condenar a los administradores como responsables concursales, puesto que la sociedad no está en situación de insolvencia actual y, por tanto, los administradores no están obligados a solicitar el concurso. La solicitud de concurso es una medida alternativa a la promoción de la disolución pero para ello es necesario que se solicite, de la misma forma que la convocatoria de junta, dentro del plazo de dos meses desde el acaecimiento de la causa de disolución. De lo contrario, los administradores serán responsables de las obligaciones sociales posteriores a esa causa ex artículo 367 LSC.

En este sentido, la concurrencia de la responsabilidad concursal y la responsabilidad por deudas tan sólo es posible en aquellos supuestos en los con anterioridad a una situación de insolvencia actual la sociedad se encuentra en una situación de pérdidas graves. Ante estas situaciones, los acreedores titulares de créditos posteriores al momento de acaecimiento de la causa de disolución, con independencia del momento en el que la sociedad entre en estado de insolvencia actual, podrán exigir el pago de las deudas a los administradores mediante el ejercicio de

${ }^{7}$ Vid. STS de 15 de octubre de 2013 (ponente: Ignacio Sancho Gargallo). En este supuesto se declara que no cabe exigir al administrador la responsabilidad ex artículo 367 LSC, por incumplimiento del deber de disolver la sociedad durante la fase de convenio, puesto que durante el mismo no corresponde este deber. En la fase de convenio se debe aplicar la normativa concursal y el administrador debe instar la liquidación de la sociedad cuando, durante la vigencia del convenio, conozca la imposibilidad de cumplir los pagos comprometidos (artículos 142 y 145 LC). 
la acción prevista en el artículo 367 LSC (ALCOVER GARAU, 2006, p. 92). Estos acreedores pueden ver satisfechos sus créditos por las dos vías: la societaria y la concursal. Desde el punto de vista de los acreedores, resulta más ventajoso el ejercicio de la acción de responsabilidad por deudas, puesto que de esta forma ven satisfechos sus créditos con anterioridad al inicio del procedimiento concursal o bien durante la tramitación del mismo y sin estar sometidos a la par conditio creditorum.

\section{La acción social de responsabilidad y el procedimiento concursal}

\section{I. Efectos de la declaración de concurso sobre la acción social de responsabilidad}

La LC permite de forma expresa el ejercicio de la acción social de responsabilidad durante la tramitación del procedimiento concursal, en atención a lo previsto en el artículo 48 quater LC. De esta forma, no hay ninguna discusión sobre la posibilidad de continuar el procedimiento de responsabilidad societaria por daños causados a la sociedad, a pesar de que con posterioridad a su inicio la sociedad sea declarada en concurso así como la de ejercitar esta acción una vez iniciado el procedimiento concursal.

A pesar de esa compatibilidad, la LC establece algunas especialidades en cuanto al régimen aplicable al ejercicio de esta acción durante la tramitación de un procedimiento concursal en relación a la legitimación activa y al juez competente.

La acción social de responsabilidad que, como es sabido, tiene como finalidad resarcir el patrimonio de la sociedad, puede ser ejercitada no sólo por la sociedad, sino también por los accionistas y por los acreedores, a pesar de que éstos con un carácter subsidiario y por cuenta y en nombre de la sociedad, que es la verdadera titular de esta acción (artículo 238 LSC). Sin embargo, cuando la sociedad ha sido declarada en concurso, una de las especialidades introducidas por la LC es que la legitimación activa corresponde de forma exclusiva a la administración concursal ${ }^{8}$. Esta legitimación encuentra justificación en el interés del concurso, puesto que la eventual condena de los administradores resarcirá el patrimonio social y, por tanto, la masa activa se verá ampliada con la indemnización por daños y perjuicios cuando los administradores sean condenados. A pesar de que consideramos que si se hubiese mantenido la legitimación al resto de sujetos, en nada hubiese perjudicado la finalidad perseguida.

Otra de las especialidades introducidas por la LC en relación a la acción social de responsabilidad es la determinación del juez competente, puesto que la Ley atribuye competencia al juez del concurso para conocer de las acciones sociales de responsabilidad por los daños causados a la persona jurídica concursada, ya sea antes o después de la declaración de concurso. Esta competencia es de carácter exclusiva y excluyente, por tanto, el juez del concurso no sólo conocerá de la acción social de responsabilidad ejercitada por la administración concursal durante la tramitación del concurso sino también la ejercitada por la sociedad, los socios o los acreedores, con anterioridad a la declaración del concurso.

${ }^{8}$ Esta legitimación activa no era exclusiva para la administración concursal en la redacción originaria de la Ley Concursal, sino que a la legitimación reconocida a la sociedad, a los socios y a los acreedores se añadía la de la administración concursal. Sin embargo, desde la modificación de la Ley Concursal por la Ley 38/2011, de 10 de octubre, tan sólo la administración concursal podrá interponer la acción social de responsabilidad durante la tramitación de un concurso. 
En esta línea, y puesto que la acción social de responsabilidad se puede ejercitar durante la tramitación del procedimiento concursal, entendemos que el artículo 60.2 LC, que trata sobre la interrupción de la prescripción, no es aplicable a esta acción. Este artículo, que ya ha sido citado con anterioridad, establece que desde la declaración hasta la conclusión del concurso quedará interrumpida la prescripción de las acciones contra socios y contra administradores, liquidadores y auditores, de la persona jurídica deudora. Como hemos comentado, la LC mantiene el ejercicio de la acción social de responsabilidad durante la tramitación del procedimiento concursal y otorga legitimación exclusiva a la administración concursal. De esta forma, si fuese posible su ejercicio no tendría ningún sentido ampliar el plazo de prescripción de estos legitimados, puesto que junto al que tenían desde la producción del daño, si es anterior a la declaración del concurso, se le sumaría el plazo de cuatro años cuyo cómputo se iniciaría cuando concluyese el concurso?.

\section{2. Coordinación de la responsabilidad concursal y la acción social de responsabilidad}

Un mismo supuesto de hecho puede cumplir los presupuestos para que sean exigibles tanto la acción social de responsabilidad como la responsabilidad concursal. Este supuesto sería aquel en el que el incumplimiento del deber de diligencia por parte de los administradores tiene como resultado la generación o agravación del estado de insolvencia. Esta situación permite la exigencia de la responsabilidad concursal si ese incumplimiento se ha producido como consecuencia de un comportamiento doloso o culposo en el grado de grave y el procedimiento concursal finaliza en liquidación. Del mismo modo, será posible exigir la responsabilidad indemnizatoria ex artículo 238 LSC si ese mismo incumplimiento ha generado un daño a la sociedad.

Ante esta situación, la LC podría haber establecido un nuevo régimen específico y único de responsabilidad en procedimientos concursales o bien adaptar la acción social a las peculiaridades del procedimiento concursal.

Sin embargo, la Ley no adoptada ninguna de estas dos soluciones sino que mantiene los diferentes regímenes de responsabilidad societaria. A pesar de que introduce las dos particularidades, que hemos comentado, si la acción se ejercita durante la tramitación del procedimiento concursal: el reconocimiento de legitimación activa, de forma exclusiva, a la administración concursal y la competencia al juez del concurso.

El ejercicio de la acción social de responsabilidad antes o durante la tramitación del procedimiento concursal tiene interés tanto para la propia sociedad como para los socios minoritarios y los acreedores. La sentencia condenatoria por el ejercicio de esta acción permitirá un reintegro al patrimonio de la sociedad, puesto que su finalidad es resarcir el patrimonio dañado, por lo que cumple una función equivalente a las acciones de reintegración del procedimiento concursal (BELLO MARTíN-CRESPO, 2005, p. 1716). De esta forma, aumenta la masa activa y los acreedores aumentarán sus expectativas de cobro. Por el contrario, el ejercicio de la acción individual de responsabilidad y la acción de responsabilidad por deudas permiten que los acreedores puedan lograr

\footnotetext{
${ }^{9}$ En sentido contrario, vid. SJM de Bilbao de 29 de diciembre de 2007: "esa previsión no impide, sin embargo, interponer la acción. Lo que hace es suspender el cómputo para su ejercicio durante el concurso, de manera que privilegia al acreedor que se ve afectado por el concurso, que no se ve forzosamente compelido a ejercitar su pretensión en el término que dispone el art. 949 del Código de Comercio, pudiendo aguardar al resultado del concurso, por el que pasaría si se aprobara el convenio, haciendo innecesario el ejercicio de otras acciones".
} 
el cobro de los créditos sin quedar sometidos a la par conditio creditorum, a pesar de que en cualquier caso la masa pasiva de la sociedad se verá reducida.

De este modo, en aquellas situaciones en las que se haya interpuesto la acción social con anterioridad a que se dicte la sentencia de calificación y condene a los administradores a indemnizar los daños causados por el fallido concursal, el juez del concurso no podría exigir la responsabilidad concursal con el fin de evitar supuestos de doble responsabilidad. En este sentido, es posible mencionar a Vázquez Albert (2004) quien afirma: "la responsabilidad concursal y la acción social constituirían regímenes alternativos, no cumulativos, siendo la responsabilidad concursal el régimen subsidiario en caso de que no ejercieran la acción social ni los administradores concursales, ni la sociedad, los socios o los acreedores de la sociedad". Si por el contrario, ha recaído condena por responsabilidad concursal y con posterioridad se interpone la acción social por considerar que hay daños pendientes de resarcimiento, la posible condena debería tener en cuenta y no incluir la indemnización ya satisfecha por los créditos concursales fallidos.

\section{La acción individual de responsabilidad y el procedimiento concursal}

\section{I. Efectos de la declaración de concurso sobre la acción individual de responsabilidad}

Como es sabido, la acción individual de responsabilidad, prevista en el artículo 24I LSC, es una acción de carácter indemnizatorio, de la misma forma que la acción social. El patrimonio objeto de resarcimiento es el de los socios o terceros a los que el propio artículo reconoce legitimación activa. Sin embargo, en el presente artículo, nuestra atención debe centrarse en los supuestos en los que el legitimado es un acreedor contractual de la sociedad porque en estas situaciones la condena del administrador tiene relevancia para la situación concursal de la sociedad. En una situación de normalidad el administrador no responde del cumplimiento del contrato, porque, a pesar de que ha sido celebrado entre estos terceros y los administradores, éstos lo hacen en nombre y por cuenta de la sociedad. Sin embargo, cuando el acreedor no obtiene la prestación debida como consecuencia del comportamiento del administrador podrá dirigir la acción individual de responsabilidad frente a éste por haber resultado lesionado su derecho crédito. Por ello, se debe determinar si dentro de estos daños están incluidas las deudas que tiene la sociedad y, por tanto, si se puede ver alterada la par conditio creditorum. En este sentido, el Tribunal Supremo 10 ha considerado que el daño directo que pueden reclamar los acreedores, en el ejercicio de la acción individual de responsabilidad, debe ser consecuencia de una actuación reprochable de los administradores en la generación o en el impago de la deuda (SAAVEDRA LÓPEZ, J.P. Y SÁNCHEZ HERNÁNDEZ, 20I4, p. 324).

En nuestra opinión, puesto que el comportamiento del administrador ha generado el incumplimiento de la obligación de la sociedad, éste debe ser responsable de la misma, puesto que forma parte del daño que ha generado. En este sentido, el daño que sufre el acreedor está comprendido por la obligación debida por la sociedad y además por las consecuencias que ese incumplimiento pueda ocasionar en su patrimonio (GIMENO-BAYÓN COBOS, 1997, p. 42). En estos casos, el acreedor puede lograr la satisfacción de un crédito que tiene frente a la sociedad con cargo al patrimonio de los administradores. Si la sociedad ha sido declarada en concurso lograría escapar de la par conditio creditorum con el perjuicio que esto puede ocasionar a aquellos acreedores concursales

${ }^{10} \mathrm{Vid}$. STS de 23 de mayo de 2014, de 20 de junio de 2013. Y entre las más recientes destaca la SJM núm. 1 de Palma de Mallorca de 29 de enero de 2016 y SAP de Barcelona de 7 de abril de 2015. 
que no están legitimados para el ejercicio de una acción individual de responsabilidad contra los administradores. En sentido contrario, SUÁREZ-LLANOS GÓMEZ (1996, p. 2502) afirma que la indemnización no puede incluir los intereses protegidos con la titularidad de un derecho de crédito, sino la que afecte a cualquier otro tipo de intereses, patrimoniales o no, que no se encuentren implicados en algún tipo de relación jurídica preexistente con la sociedad.

Consideramos que es relevante determinar cuáles son los efectos de la declaración de concurso sobre el ejercicio de la acción individual de responsabilidad, es decir, si durante la tramitación del procedimiento concursal los acreedores pueden interponer la acción individual, o bien deben esperar hasta la finalización del mismo, y si el proceso que resuelve esta acción debe interrumpirse o bien seguir su curso si la sociedad es declarada en concurso.

La determinación de los efectos de la declaración de concurso y la compatibilidad con la responsabilidad concursal nos conduce al análisis de los artículos 48 quater y 60.2 y 3 LC, por ser los únicos en la normativa concursal que tratan sobre la coordinación de la responsabilidad de los administradores.

El primer artículo que analizaremos es el 48 quater LC que lleva por título "efectos de la declaración de concurso sobre las acciones contra los administradores de las sociedades deudoras". Consideramos que este artículo no resulta aplicable puesto que tan sólo hace referencia a "las acciones de responsabilidad de la persona jurídica concursada contra sus administradores (...)”, y las únicas acciones que corresponden a la sociedad son las acciones sociales de responsabilidad (GARCÍA MARTíNEZ, 2006, p. 33).

El citado artículo otorga legitimación activa para el ejercicio de la acción social de responsabilidad a la administración concursal. En este sentido, es comprensible esta legitimación, puesto que se está protegiendo a la masa activa de la sociedad. Debido a que la acción individual tiene como finalidad resarcir el patrimonio individual de socios y terceros, y en nada afecta a la reintegración del patrimonio social, la administración concursal no está legitimada para su ejercicio.

Como hemos comentado, la LC también atribuye competencia al juez del concurso para el conocimiento de la acción social de responsabilidad. A la vista de la actual redacción del artículo 8 LC, el juez es competente para todas las acciones sociales de responsabilidad, interpuestas tanto antes como después de la declaración de concurso. Sin embargo, consideramos que esta previsión no es aplicable a la acción individual de responsabilidad, por lo que el juez del concurso no es competente para conocerla.

Por el contrario, consideramos plenamente aplicable a la acción individual de responsabilidad el artículo 60 LC que trata sobre la "interrupción de la prescripción". Este artículo, que también ha sido analizado, prevé en el apartado 2: "desde la declaración hasta la conclusión del concurso quedará interrumpida la prescripción de las acciones contra socios y contra administradores, liquidadores y auditores de la persona jurídica”. Esta interrupción de la prescripción debe ser interpretada como la imposibilidad de ejercitar la acción desde la declaración del concurso hasta la conclusión, puesto que de lo contrario los acreedores verían aumentado el plazo de prescripción sin justificación alguna 
(GARCÍA MARTínEZ, 2006, pp. 33). Esta imposibilidad de ejercicio, como hemos comentado, es también aplicable a la responsabilidad por deudas ex artículo 367 LSC pero no a la acción social de responsabilidad, porque el artículo 48 quater LC permite su ejercicio durante la tramitación concursal"'.

\subsection{Coordinación de la responsabilidad concursal y la acción individual de responsabilidad}

La LC no se pronuncia sobre la posibilidad de ejercitar la acción individual de responsabilidad en situaciones en las que la sociedad se encuentra declarada en concurso. A pesar de que a priori no hay un conflicto entre la acción individual de responsabilidad y la declaración de concurso, puede ocurrir que la indemnización a la que haya sido condenado el administrador consista en el pago total o parcial del crédito que un acreedor ostente contra la sociedad.

En nuestra opinión, la responsabilidad concursal tiene prioridad sobre la acción individual de responsabilidad. Los acreedores no pueden ejercitar la acción individual de responsabilidad una vez declarado el concurso de la sociedad deudora y aquellas interpuestas deben quedar interrumpidas hasta la finalización del concurso en aras a un correcto funcionamiento del procedimiento concursal (GUERRERO LEBRÓN, M.J. y GÓMEZ PORRÚA, 2005, P. 1982). De lo contrario, los acreedores podrían cobrar de forma extra concursal el derecho de crédito, a pesar de que lo sería en forma de resarcimiento por los daños ocasionados por el administrador en su patrimonio. De esta forma, el juez competente para resolver la acción individual de responsabilidad ejercitada o reanudada una vez concluido el concurso deberá tener en consideración el pago de los créditos efectuado por la propia sociedad deudora y por el administrador declarado responsable concursal, para detraerlo de la posible condena del administrador como responsable por los daños causados en el patrimonio del acreedor.

La LC no prevé un precepto que expresamente impida el ejercicio de la acción individual de responsabilidad cuando la sociedad ha sido declarada en concurso ni la interrupción del procedimiento hasta la finalización del mismo. Sin embargo, consideramos que de lege ferenda la declaración de concurso debería impedir el ejercicio de la acción individual de responsabilidad así como la ejecución de aquellas sentencias en las que se haya obtenido condena favorable, puesto que una condena favorable al ejercicio de la acción individual de responsabilidad permitiría el cobro de los créditos que los acreedores tienen contra la sociedad sin quedar sometido a las reglas del concurso(LóPEZ DE MEDRANO, 2007, p. 4I; QUIJANO GONZÁLEZ, 2009, p. 39).

En un sentido contrario, a tenor de lo dispuesto en la LC, la mayoría de la doctrina se muestra favorable al ejercicio de la acción individual de responsabilidad, a pesar de que la sociedad haya sido declarada en concurso. Estos autores consideran que la declaración de concurso de la sociedad en nada afecta a la acción individual de responsabilidad, por lo que los acreedores pueden interponer esta acción. En opinión de MUÑOZ PLANAS y MUÑOZ PAREDES (2005, pP. 2179 y 2180) y de ESTEBAN VELASCO (2008, pP. 224 y 225) no es posible impedir el ejercicio de la acción individual de responsabilidad ya que se dirige contra los administradores y no contra la sociedad que es la que está en concurso, por tanto, no se altera la par conditio creditorum. En este sentido, consideran que si el legislador hubiese querido impedir el ejercicio de esta acción durante la tramitación del procedimiento concursal o bien alterar de algún modo su régimen lo hubiese hecho, del mismo modo que lo ha previsto para la acción social de responsabilidad y la responsabilidad por deudas (QUIJANO GONZÁLEZ, 20I5). De esta forma, se ha considerado que la condena de los administradores tiene como finalidad la reparación de un daño ocasionado en el patrimonio individual de socios y de terceros, por tanto, queda excluida la satisfacción del crédito que el tercero

${ }^{11}$ Vid. STS de 22 de diciembre de 2014. 
pueda tener contra la sociedad. Sin embargo, si la condena del administrador incluyera el pago de la deuda, el administrador que haya efectuado el pago sustituirá al acreedor en la lista de acreedores del concurso (BELTRÁN SÁNCHEZ, 2006, p. 977). El argumento principal de estos autores para defender una compatibilidad de la acción individual y el procedimiento concursal es que el acreedor se dirige contra el administrador como tercero cuyo patrimonio ha resultado dañado por el comportamiento del administrador, por lo que no lo hace en concepto de acreedor concursal (GARCÍA-CRUCES GONZÁLEZ, 2008, p. 286). De esta forma, el ejercicio de la acción individual de responsabilidad no se deberá ver perjudicado por la declaración de concurso de la sociedad. No obstante, si el acreedor logra el cobro del crédito sobre la base de una condena estimatoria de la acción individual de responsabilidad, el juez del concurso deberá tenerlo en consideración en la reducción de la cuantía del déficit concursal y, por tanto, en la eventual condena de los administradores como responsables concursales (BELLO MARTíN-CRESPO, 2005, pp. 1730 y 173I). En caso de que el patrimonio del administrador no sea suficiente para reparar todos los daños, la parte pendiente de la condena que corresponda a la deuda tendrá la consideración de crédito concursal y la parte pendiente del resto de la indemnización seguirá teniendo la consideración de crédito contra el administrador (QUIJANO GONZÁLEZ, 2009, p. 37).

Para evitar problemas de coordinación, esta doctrina ha considerado que de lege ferenda el juez del concurso debería ser competente para el enjuiciamiento de la acción individual de responsabilidad cuando el concurso sea calificado culpable, con el fin de lograr una coordinación entre la acción individual de responsabilidad y la responsabilidad concursal. De esta forma, el juez puede otorgar prioridad a la responsabilidad concursal y tan sólo exigir la responsabilidad ex artículo 24I LSC una vez cubierta la primera, por beneficiar ésta a todos los acreedores frente a los que beneficia la condena por la acción individual de responsabilidad que es a aquellos que hayan ejercitado la acción (ALONSO UREBA, 2004, p. 99; FERNÁNDEZ DE LA GÁNDARA, 2004, p. 7I8; MAMBRILLA RIVERA, 2004, p. 2857).

En este sentido, también cabe precisar que los Tribunales, recogiendo el tenor literal de la LC, han considerado de forma mayoritaria que la acción individual de responsabilidad no resulta afectada por la declaración de concurso' $^{12}$. La razón principal para sustentarlo es que no hay posibilidad de solapamiento, en el sentido que el daño que sufren los acreedores por el impago de las deudas se debe considerar indirecto y no directo, que es el que estaría cubierto por la acción individual de responsabilidad, por tanto, en nada afecta a la masa patrimonial que es la protegida por el procedimiento concursal ${ }^{13}$. En este sentido, la acción individual de responsabilidad puede promoverse después de declarado el concurso y en el caso de que ya estuviese planteado desde antes, seguirá su

12 Vid. SAP Barcelona de 7 de abril de 2015, en este supuesto el administrador no resulta condenado por la acción individual de responsabilidad porque no se ha acreditado la conducta dolosa imputable al administrador ni la relación de causalidad. Sin embargo, se admite la compatibilidad de la acción individual de responsabilidad y el procedimiento concursal. En el mismo sentido, SJM núm. 1 de Palma de Mallorca de 15 de octubre de 2015, SJM núm. 2 de Bilbao de 9 de enero de 2015, SAP Córdoba de 26 de junio de 2012, SAP La Coruña de 23 de marzo de 2012, SJM núm. 8 de Madrid de 19 de septiembre de 2013, SAP Las Palmas de 6 de marzo de 2009, AAP Madrid de 18 de diciembre de 2009 y 13 de noviembre de 2007.

Y en sentido opuesto a esa compatibilidad se pronuncian el AJM núm. 10 de Santander de 13 de febrero de 2006 y el AJM núm. 1 de Oviedo de 13 de diciembre de 2005.

${ }^{13}$ Vid. SJM de Vigo de 27 de mayo de 2014. 
procedimiento ${ }^{14}$. También se ha afirmado que el silencio del legislador no puede ser interpretado como un olvido sino como una compatibilidad expresa entre el procedimiento concursal y la acción individual de responsabilidad ${ }^{15}$.

\section{Conclusiones}

La compatibilidad del procedimiento concursal y las diferentes acciones societarias de los administradores así como entre estas acciones y la responsabilidad concursal no es una cuestión pacífica en la doctrina ni en la jurisprudencia, en atención a la protección de la par conditio creditorum que trata de defender el procedimiento concursal.

En el caso de la responsabilidad por deudas ex artículo 367 LSC, no hay ninguna duda sobre la incompatibilidad con el procedimiento concursal. Pues la LC prevé que aquellos procedimientos iniciados para reclamar esta responsabilidad con anterioridad a la declaración de concurso quedarán paralizados y aquellos no iniciados no se podrán iniciar hasta que finalice el procedimiento concursal. $Y$ en sentido contrario, en el caso de la acción social de responsabilidad, la LC admite expresamente su compatibilidad con el procedimiento concursal. A pesar de que se introducen algunas alteraciones en su régimen relativas a la legitimación activa y al juez competente.

La mayor dificultad se encuentra con la acción individual de responsabilidad, puesto que la LC no se pronuncia sobre ella. En nuestra opinión, la declaración de concurso debería impedir el ejercicio de la acción individual de responsabilidad así como la ejecución de aquellas sentencias en las que se haya condenado a los administradores sociales, pesar de que la ley no lo contempla y, por ello, los Tribunales proclamen su compatibilidad. La razón para defender nuestra postura es que la condena de los administradores sociales ante el ejercicio de la acción individual de responsabilidad puede también incluir la deuda de la sociedad, puesto que puede llegar a formar parte del daño directo causado por los administradores. Si el procedimiento para exigir la acción individual de responsabilidad continúa, a pesar de que la sociedad sea declarada en concurso o bien puede iniciarse una vez la sociedad es declarada en concurso, los acreedores podrían logar burlar la par conditio creditorum, que es precisamente lo que la LC trata de evitar cuando prevé la incompatibilidad de la responsabilidad por deudas ex artículo 367 LSC y el procedimiento concursal.

${ }^{14}$ Vid. SAP Alicante de 3 de abril de 2013.

${ }^{15} \mathrm{Vid}$. SAP Córdoba de 30 de septiembre de 2013, de 26 de febrero de 2012 y de 22 de marzo de 2013 y SAP de Jaén de 12 de mayo de 2011. 


\section{Lista de referencias bibliográficas}

ALCOVER GARAU, G. (2006). El ámbito de responsabilidad de los administradores en los nuevos artículos 262.5 de la Ley de Sociedades Anónimas y 105.5 de la Ley de Sociedades de Responsabilidad Limitada. Revista de Derecho de Sociedades 26/2006, pp. 85 a 93.

ALONSO UREBA, A. (2004). El artículo 48.2 LC y el marco de relaciones de la responsabilidad concursal del artículo 172.3 LC con la responsabilidad de los auditores y con las acciones societarias de responsabilidad de los administradores y liquidadores. Revista de Derecho Concursal y Para concursal I/2004, pp. 9 I a 107.

BELLO MARTÍN-CRESPO, M.P. (2005). Responsabilidad civil de administradores de sociedades de capital y ley concursal. En AA.W., Estudios sobre la Ley concursal. Libro homenaje a Manuel Olivencia (Vol. 2). Madrid: Marcial Pons, pp. 1677 a 1735.

BELTRÁN SÁNCHEZ, E. M. (2006). Comentario al artículo 48 LC. En A. J. Rojo Fernández-Río y E. M. Beltrán Sánchez, Comentario de la Ley Concursal (Vol. I). Madrid: Civitas, pp. 960 a 988.

BELTRÁN SÁNCHEZ, E. M. (20II). La responsabilidad de los administradores por las obligaciones sociales. En E. M. Beltrán Sánchez y A. J. Rojo Fernández-Río, La responsabilidad de los administradores. Valencia: Tirant lo Blanch, pp. 255 a 304.

ESTEBAN VELASCO, G. (2008). La acción individual de responsabilidad. En E. M. Beltrán Sánchez y A. J. Rojo Fernández-Río, La responsabilidad de los administradores. Valencia: Tirant lo Blanch, Pp. 153 a 226.

FERNÁNDEZ DE LA GÁNDARA, L. (2004). La responsabilidad concursal de los administradores de sociedades de capital. En L. Fernández de la Gándara y M. M. Sánchez Álvarez, Comentarios a la Ley Concursal. Madrid: Marcial Pons, pp. 70I a 721.

GARCÍA-CRUCES GONZÁLEZ, J.A. (2008). La responsabilidad concursal. En E. M. Beltrán Sánchez y A. J. Rojo Fernández-Río, La responsabilidad de los administradores, Valencia: Tirant lo Blanch, Pp. 28 I a 336.

GARCÍA MARTÍNEZ, A. (2006). Declaración del concurso: responsabilidad de los administradores de la sociedad concursad. luris: actualidad y práctica del Derecho 101/2006, pp. 28 a 37.

GIMENO-BAYÓN COBOS, R. (1997). Algunos aspectos conflictivos de la responsabilidad de los administradores por no promover la disolución de las sociedades anónimas concurriendo causa. Cuadernos de Derecho Judicial 2 I/I997, pp. 25 a 142. 
GONZÁLEZ VÁZQUEZ, J.C. (2004). Disposición final Vigésima. Reforma de la Ley de Sociedades Anónimas. En J. Sánchez Calero y V. A. Guilarte Gutiérrez, Comentarios a la Legislación Concursal. Valladolid: Lex Nova, pp. 3799 a 3814.

GUERRERO LEBRÓN, M.J. Y GÓMEZ PORRÚA, J.M. (2005). La responsabilidad de los administradores de sociedades de capital en situación concursal. En AA.VV., Estudios sobre la Ley Concursal: libro homenaje a Manuel Olivencia (Vol. 2). Madrid: Marcial Pons, pp. 1965 a 1988.

LÓPEZ DE MEDRANO, F. (2007). Las acciones de daños y de cobertura del pasivo en el concurso de acreedores. Anuario de Derecho Concursal I2/2007, pp. 33 a 73.

MAMBRILLA RIVERA, V. (2004). Comentario al artículo 172. Sentencia de calificación. En J. Sánchez Calero y V. Guilarte Gutiérrez, Comentarios a la Legislación Concursal (T. II). Valladolid: Lex Nova.

MUÑOZ GARCÍA, A. (2007). La responsabilidad civil preconcursal de los administradores en las sociedades de capital. Efectos del Convenio Concursal Societario. Revista de Derecho de Sociedades 28/2007, pp. 183 a 215.

MUÑOZ PLANAS, J.M. Y MUÑOZ PAREDES, J.M. (2005). Repercusiones del concurso de la sociedad sobre la responsabilidad de los administradores. En AA.VV., Estudios sobre la Ley Concursal. Libro homenaje a Manuel Olivencia (Vol. II). Madrid: Marcial Pons, pp. 2 I 73 a 2204.

PERDICES HUETOS, A. (2005). La responsabilidad de los administradores por deudas sociales a la luz de la ley concursal. Indret, julio 2005.

QUIJANO GONZÁLEZ, J. (20I5). Coordinación de acciones societarias (social, individual y por deudas) y concursales de responsabilidad. Revista de Derecho Concursal y Paraconcursal 22/2015, PP. 43 a 50

QUIJANO GONZÁLEZ, J. (2009). Responsabilidad societaria y concursal de administradores: de nuevo sobre la coordinación y el marco de relaciones. Revista de Derecho Concursal y Paraconcursal, 10/2009, pp. 19 a 48.

RODRÍGUEZ RUIZ DE VILLA, D. (2004). El artículo 262.5 de la Ley de Sociedades Anónimas: sobre el plazo de dos meses y los efectos del convenio concursal (comentario a la STS de 23 de febrero de 2004). Anuario de Derecho Concursal 2/2004, pp. 83 a 1 I 7. 
SAAVEDRA LÓPEZ, J.P. Y SÁNCHEZ HERNÁNDEZ, R. (2014). ¿Es la acción individual de responsabilidad frente a los administradores una herramienta real de protección del acreedor de una sociedad de capital en concurso?. Revista de Derecho de Sociedades 43/20I4, pp. 303 a 331.

SEQUEIRA MARTÍN, A., SACRISTÁN BERGIA, F., MUÑOZ GARCÍA, A. (2006). La relación entre el concurso y la situación de pérdidas patrimoniales graves como causa disolutoria en la sociedad anónima. Diario La Ley 6610, de 15 de diciembre de 2006, pp. 1745 a 1763.

SUÁREZ-LLANOS GÓMEZ, L. (1996). La responsabilidad por deudas de los administradores de sociedades anónimas. En J. L. Iglesias Prada, Estudios Jurídicos en homenaje al Profesor Aurelio Menéndez (Vol. 2). Madrid: Civitas, pp. 248I a 2508.

VALPUESTA GASTEMIZA, E. (20I5). La interrupción de la acción individual contra administradores sociales y auditores por la declaración de concurso. Anuario de Derecho Concursal 36/20I5, Pp. 34I a 355.

VÁZQUEZ ALBERT, D. (2004). El concurso de las personas jurídicas: la responsabilidad de los administradores sociales. Revista Jurídica de Catalunya 4/2004, pp. 1055 a 1076.

Abreviaturas

AAP Auto Audiencia Provincial

AJM Auto Juzgado de lo Mercantil

LC Ley Concursal

LSC Ley de Sociedades de Capital

SAP Sentencia Audiencia Provincial

SJM Sentencia Juzgado de lo Mercantil

STS Sentencia Tribunal Supremo 